\title{
Measuring diaphragm shortening using ultrasonography to predict extubation success
}

\author{
Gerard J Criner
}

It is estimated that approximately 800000 US patients annually require mechanical ventilation to treat acute respiratory failure due to medical disorders, trauma or the postoperative period. ${ }^{1}$ The use of mechanical ventilation is projected to increase significantly in the next few decades due to the impact of aging baby bloomers requiring more critical care resources. ${ }^{2}$ Although life-saving, the prolonged use of mechanical ventilation is associated with significant complications such as nosocomial pneumonia, barotrauma, patient

Correspondence to Gerard I Criner, Pulmonary and Critical Care Medicine and Temple Lung Center, Temple University School of Medicine, 745 Parkinson Pavilion, 3401 North Broad Street, Philadelphia, PA 19140,

USA; gerard.criner@tuhs.temple.edu discomfort, airway complications and respiratory muscle atrophy and accounts for a substantial percentage of the costs encountered by patients receiving care in the intensive unit. $^{3}$ The process of weaning is a key element of mechanical ventilation and can occupy almost $50 \%$ of the total duration of mechanical ventilation. ${ }^{4}$ Unnecessary delays in weaning patients who are physiologically able to wean from mechanical ventilation may increase the morbidity and mortality associated with prolonged ventilation and contribute to excessive medical expenditures. ${ }^{5}$

Trying to decide when to wean patients from mechanical ventilation can be challenging for the clinician and has been reported by some to be more art than science. ${ }^{6}$ The influence of the nurse or physician's experience in assessing the patient's readiness to wean, the psychological profile or mental preparedness of the patient and objective indices of physiological factors crucial to enable patients to sustain spontaneous ventilation have all been reported as important factors in determining the patient's readiness to wean. ${ }^{7}$ However, recent data suggests that subjective decision-making of the clinicians is often wrong when predicting successful weaning outcome. Some authors have reported that the clinical prediction of extubation success is often incorrect with the decision often skewed towards the continuation of mechanical ventilation. ${ }^{8}$

Objective and precise parameters that can determine the optimal timing of extubation are needed, but extremely limited. Bedside measurements used to predict weaning outcomes such as the level of spontaneous minute ventilation during unassisted breathing, ability to increase maximum voluntary ventilation, magnitude of negative inspiratory force generation and rate of breathing frequency have done little to improve the timing of successful weaning from mechanical ventilation. ${ }^{9}$ Use of more exquisite techniques to predict weaning outcome during 
spontaneous breathing trials have included changes in neural drive assessed by $\mathrm{P} 0.1$, work of breathing estimated by transpulmonary pressure or indirect calorimetry, and changes in oxygen uptake and gastric mucosal pH. ${ }^{9}$ Although each of these techniques showed promise in predicting weaning outcome, none ever achieved broad-based use due to their inconsistencies in demonstrating reproducible outcomes, relative invasiveness, requirements for complicated techniques or equipment, need for additional specially trained personnel or impracticality when applied to broad-based patient populations receiving mechanical ventilation. The rapid shallow breathing index (RSBI) superseded these other techniques because of its ease of use and simplicity in measurement and interpretation. ${ }^{10}$ The RSBI can provide useful information regarding weaning success during spontaneous breathing trials or in those receiving mechanical ventilation for durations $<1$ week, but its value is limited to predict successful extubation in those being weaned using pressure support or requiring mechanical ventilation $>7$ days. ${ }^{11}$

Weaning from mechanical ventilation, especially those who are classified as difficult to wean or prolonged weaning, are more likely to have respiratory muscle dysfunction as a major contributing cause to their inability to wean from mechanical ventilation. ${ }^{12} 13$ Optimal function of the diaphragm, the primary muscle of inspiration, is key to resuming successful spontaneous ventilation regardless of the cause of respiratory failure. Contrary to prior beliefs, controlled mechanical ventilation for as little as $24 \mathrm{~h}$ has been associated with development of human diaphragm muscle atrophy. ${ }^{14}$ Direct measurement of diaphragm function as a predictor of extubation success or failure may be important in assessing weaning outcome, but particularly in patients receiving mechanical ventilation defined as difficult to wean or prolonged weaning where respiratory pump function may have an even more pivotal role. ${ }^{12}$ Changes in diaphragm vertical excursion using M-mode ultrasound had previously been reported useful in predicting extubation outcomes. Kim et al used M-mode ultrasonography to measure vertical excursions $<10 \mathrm{~mm}$ or paradoxical movement of the diaphragm in 88 medical intensive care unit patients who received mechanical ventilation $>48 \mathrm{~h}$ and met criteria for spontaneous breathing trials. ${ }^{15}$ Patients with limited or paradoxical diaphragmatic dome excursions had longer weaning times and total ventilation times than patients without diaphragm dome dysfunction and also had higher rates of primary and secondary weaning failures. However, diaphragm dome imaging fails to directly visualise diaphragm muscle function and mitigating factors such as size of breath, abdominal or chest wall compliance, overlying rib cage or abdominal muscle activity, obesity or ascites can affect regional and global diaphragm motion. Direct imaging of changes in diaphragm thickness during spontaneous breathing (ie, muscle shortening) may provide a more accurate assessment of the diaphragm as a contractile muscle and the propensity of the patient to have the necessary respiratory pump function to successfully reassume spontaneous respiration.

DiNino et $a l^{16}$ report a prospective examination of the use of diaphragm ultrasound as a predictor of extubation from mechanical ventilation in 63 mechanically ventilated patients. Specifically, they evaluated if ultrasound derived measures of diaphragm contractile function during spontaneous breathing, rather than diaphragm motion, can be used to determine extubation success or failure. Diaphragm thickness (tdi) was measured in the zone of apposition of the diaphragm with the lateral rib cage using a $7-10 \mathrm{MHz}$ ultrasound transducer. Per cent change in tdi between end-expiration and endinspiration (change tdi $\%$ ), a measure of diaphragm shortening or its contractive action, was calculated during either spontaneous breathing or pressure support weaning trials. Measures of diaphragm thickness at end-expiration and the components of breathing pattern (tidal volume, respiratory rate and the derived RSBI) were also measured. In the 63 patients studied, 27 patients were weaned with spontaneous breathing trials and 36 weaned with pressure support. The patients had been on mechanical ventilation prior to weaning attempts for a mean $\pm \mathrm{SD}$ of $5.19 \pm 4.13$ days. The combined sensitivity and specificity of change in tdi $\% \geq 30 \%$ for extubation success was $80 \%$ and $71 \%$, respectively. The positive and negative predictive values were $91 \%$ and $63 \%$, respectively. The ROC was 0.79 for change in tdi $\% \geq 30 \%$ and 0.55 for RSBI.

Some limitations existed in the study. Measures were made only of the right hemidiaphragm, the patient population was small in number and included only medical patients, patients for the most part were ventilated only short periods of time and measurements of diaphragm thickness were not made immediately before the time of extubation. Furthermore, a combined index of the product of diaphragm shortening ( $\%$ change in tdi) with the surrogate measure of diaphragm strength (tdi at end-expiration) failed to improve extubation prediction. This factor may underscore the effects of a small patient number, restricted range of mechanical ventilation days and prolonged interval time between the measurements of diaphragm function using ultrasonography with the actual time of extubation.

Regardless of this study's limitations, however, this study highlights another promising application that bedside ultrasonography may provide for the clinician managing patients who require mechanical ventilation. Ultrasonography is becoming an ever increasingly multifunctional tool in the intensive care unit for a variety of applications that range from imaging guidance for the placement of intravascular catheters, assessment of cardiac function, assessment of intravascular volume status, identification of body cavity collections that require drainage or sampling and an evolving role in the assessment of the patient's ability to wean from mechanical ventilation. Mongodi et al recently highlighted how combined echocardiography and lung ultrasonography during a spontaneous breathing trial discovered unsuspected left ventricular diastolic dysfunction that caused the accumulation of extravascular lung water that led to repeated weaning failure. ${ }^{17}$ Soummer et al in an observational study in 100 patients demonstrated that lung ultrasonography determination of decreased aeration during spontaneous breathing trials precipitated by extensive lung derecruitment was associated with poor weaning outcome. ${ }^{18}$

Although the above studies require extensive prospective investigation, they highlight the potential important information of dynamic performance that real-time ultrasound assessment of lung, diaphragm and cardiac functions may provide to the clinician aid in the prediction of weaning outcomes.

Competing interests None.

Provenance and peer review Commissioned; internally peer reviewed.

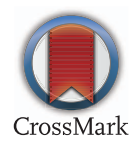

To cite Criner GJ. Thorax 2014;69:402-404.

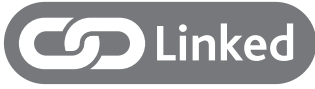

http://dx.doi.org/10.1136/thoraxjnl-2013-204111

Thorax 2014;69:402-404.

doi:10.1136/thoraxjnl-2013-204920 


\section{REFERENCES}

1 Wunsch H, Linde-Zwirble WT, Angus DC, et al. The epidemiology of mechanical ventilation use in the United States. Crit Care Med 2010;38:1947-53.

2 Needham DM, Bronskill SE, Calinawan JR, et al. Projected incidence of mechanical ventilation in Ontario to 2026: preparing for the aging baby boomers. Crit Care Med 2005;33:574-9.

3 McConville JF, Kress JP. Weaning patients from the ventilator. N Engl J Med 2013;368:1068-9.

4 Esteban A, Alia I, Ibanez J, et al. Modes of mechanical ventilation and weaning. A national survey of Spanish hospitals. The Spanish Lung Failure Collaborative Group. Chest 1994;106:1188-93.

5 Maclntyre NR, Cook DJ, Ely EW Jr, et al. Evidence-based guidelines for weaning and discontinuing ventilatory support: a collective task force facilitated by the American College of Chest Physicians; the American Association for Respiratory Care; and the American College of
Critical Care Medicine. Chest 2001;120(6 Suppl):375S-95S.

6 Milic-Emili J. Is weaning an art or a science? Am Rev Respir Dis 1986;134:1107-8.

7 Blackwood B. The art and science of predicting patient readiness for weaning from mechanical ventilation. Int J Nurs Stud 2000;37:145-51.

8 Stroetz RW, Hubmayr RD. Tidal volume maintenance during weaning with pressure support. Am J Respir Crit Care Med 1995;152:1034-40.

9 Laghi F, Morales D. Predictors of Weaning from Mechncail Ventilation. Eur Respir Monogr 2012;55:169-90.

10 Yang KL, Tobin MJ. A prospective study of indexes predicting the outcome of trials of weaning from mechanical ventilation. $N$ Engl J Med

1991;324:1445-50.

11 Tokioka H, Saito S, Niguma T, et al. The effect of pressure support ventilation on breathing patterns and the work of breathing. Kokyu To Junkan 1990;38:269-72.

12 Funk GC, Anders S, Breyer MK, et al. Incidence and outcome of weaning from mechanical ventilation according to new categories. Eur Respir J 2010;35: 88-94.

13 Boles JM, Bion J, Connors A, et al. Weaning from mechanical ventilation. Eur Respir J 2007;29:1033-56.

14 Levine S, Nguyen T, Taylor N, et al. Rapid disuse atrophy of diaphragm fibers in mechanically ventilated humans. N Engl J Med 2008;358:1327-35.

15 Kim WY, Suh HJ, Hong SB, et al. Diaphragm dysfunction assessed by ultrasonography: influence on weaning from mechanical ventilation. Crit Care Med 2011;39:2627-30.

16 DiNino E, Gartman E, Sethi J, et al. Diaphragm Ultrasound as a Predictor of Successful Extubation from Mechnaical Ventilation. Thorax 2014;69:431-5.

17 Mongodi S, Via G, Bouhemad B, et al. Usefulness of combined bedside lung ultrasound and echocardiography to assess weaning failure from mechanical ventilation: a suggestive case ${ }^{*}$. Crit Care Med 2013;41:e182-5.

18 Soummer A, Perbet S, Brisson $\mathrm{H}$, et al. Ultrasound assessment of lung aeration loss during a successful weaning trial predicts postextubation distress* ${ }^{*}$. Crit Care Med 2012;40:2064-72. 